\title{
Procedural and Long-term Ischemic Outcomes of Tight Subtotal Occlusions Treated with Orbital Atherectomy: An ORBIT II Subanalysis
}

Michael S. Lee, M.D. ${ }^{{ }^{*}}$, Richard A. Shlofmitz, M.D. ${ }^{b}$, Evan Shlofmitz, D.O. ${ }^{c}$, Ann N. Behrens, B.S. ${ }^{\mathrm{d}}$, George Revtyak, M.D. ${ }^{\mathrm{e}}$, Brad J. Martinsen, Ph.D. ${ }^{\mathrm{d}}$, Jeffrey W. Chambers, M.D. ${ }^{\mathrm{f}}$

a. UCLA Medical Center, 100 Medical Plaza Suite 630, Los Angeles, CA 90095, USA, mslee@mednet.ucla.edu

b. St. Francis Hospital—The Heart Center, 100 Port Washington Blvd., Suite 105, Roslyn, NY 11576, USA, hartfixr1@gmail.com

c. Cardiovascular Research Foundation, 1700 Broadway, 8th Floor, New York, NY 10017, USA, eshlofmitz@gmail.com

d. Scientific Affairs, Cardiovascular Systems, Inc., 1225 Old Highway 8 NW, St. Paul, MN

55112, USA, abehrens@csi360.com, bmartinsen@csi360.com

e. IU Health Physicians Cardiology, 1801 N. Senate Blvd., Suite 310, Indianapolis, IN 46202,

USA, grevtyak@IUHealth.org

f. Metropolitan Heart and Vascular Institute, Mercy Hospital, 4040 Coon Rapids Blvd, Minneapolis, MN 55433, USA, J.Chambers@mhvi.com

This is the author's manuscript of the article published in final edited form as:

Lee, M. S., Shlofmitz, R. A., Shlofmitz, E., Behrens, A. N., Revtyak, G., Martinsen, B. J., \& Chambers, J. W. (2018). Procedural and long-term ischemic outcomes of tight subtotal occlusions treated with orbital Atherectomy: An ORBIT II subanalysis. Cardiovascular Revascularization Medicine. https://doi.org/10.1016/j.carrev.2018.09.011 
*Corresponding author:

Michael S. Lee, M.D.

Associate Professor of Medicine

100 Medical Plaza Suite 630

Los Angeles, CA 90095

Office: $310-696-9523$

Email: mslee@mednet.ucla.edu

Funding sources: Cardiovascular Systems, Inc. sponsored the ORBIT II study and financially supported the statistical analysis for the subtotal occlusion subanalysis.

Declaration of interest: Michael S. Lee, Richard Shlofmitz, Evan Shlofmitz, and Jeffrey

Chambers have consulting agreements with Cardiovascular Systems, Inc. Brad Martinsen and Ann Behrens are employed by Cardiovascular Systems, Inc. George Revtyak has consulting agreements with Cardiovascular Systems, Inc., Terumo, and Lilly. 


\begin{abstract}
Background/Purpose: Orbital atherectomy is an effective treatment strategy to modify severely calcified coronary lesions prior to stent placement. Traversing a severely calcified subtotal occlusion with the crown may be more challenging compared with a less severely stenotic lesion. The purpose of this ORBIT II subanalysis was to evaluate outcomes post-orbital atherectomy (OA) treatment of lesions with $\geq 95 \%$ stenosis.

Methods/Materials: ORBIT II, a single-arm, prospective, multicenter trial, enrolled 443 subjects with severely calcified coronary lesions. Patients with chronic total occlusions were excluded from the trial. Subjects with the OA device activated were stratified based on preprocedure percent stenosis: $\geq 95 \%$ stenosis $(\mathrm{N}=91)$ and $<95 \%$ stenosis $(\mathrm{N}=341)$. Procedural success and 3-year major adverse cardiac event (MACE) rates were compared.
\end{abstract}

Results: The severe angiographic complications rates were $6.6 \%$ and $6.7 \%$ in the $\geq 95 \%$ and $<95 \%$ stenosis groups, respectively. There was no significant difference in procedural success (94.5\% vs. $88.3 \%, \mathrm{p}=0.120)$. 3-year MACE rates were similar $(27.1 \%$ vs. $22.5 \%, \mathrm{p}=0.548)$, as were the rates of cardiac death $(5.7 \%$ vs. $7.1 \%, \mathrm{p}=0.665)$ and $\mathrm{MI}(7.9 \%$ vs. $12.1 \%, \mathrm{p}=0.244)$. The TVR rate was higher in the $\geq 95 \%$ stenosis group $(19.1 \%$ vs. $7.5 \%, \mathrm{p}=0.004)$.

Conclusions: In ORBIT II, OA treatment of lesions with $\geq 95 \%$ stenosis resulted in a high rate of procedural success. Although the 3 -year revascularization rate was higher in the $\geq 95 \%$ stenosis group, it is not unexpected given the challenge of treating such complex lesions. The results of this analysis suggest that OA may be a reasonable treatment strategy for tight, severely calcified subtotal occlusions. 
Keywords: atherectomy, calcification, percutaneous coronary intervention, subtotal occlusion

Summary: The purpose of this ORBIT II subanalysis was to evaluate outcomes post-orbital atherectomy $(\mathrm{OA})$ treatment of lesions with $\geq 95 \%$ stenosis. In ORBIT II, OA treatment of lesions with $\geq 95 \%$ stenosis resulted in a high rate of procedural success. Although the 3 -year revascularization rate was higher in the $\geq 95 \%$ stenosis group, it is not unexpected given the challenge of treating such complex lesions. The results of this analysis suggest that OA may be a reasonable treatment strategy for tight, severely calcified subtotal occlusions. 


\author{
Abbreviations: \\ $\mathrm{ACC}=$ American College of Cardiology \\ $\mathrm{AHA}=$ American Heart Association \\ $\mathrm{CTO}=$ chronic total occlusion \\ eGFR = estimated glomerular filtration rate \\ IVUS = intravascular ultrasound \\ LAD = left anterior descending artery \\ MACE $=$ major adverse cardiac events \\ $\mathrm{MI}=$ myocardial infarction \\ MLD = minimal luminal diameter \\ $\mathrm{PCI}=$ percutaneous coronary intervention \\ $\mathrm{OA}=$ orbital atherectomy \\ OAS = orbital atherectomy system \\ $\mathrm{RCA}=$ right coronary artery \\ $\mathrm{RVD}=$ reference vessel diameter \\ TLR $=$ target lesion revascularization \\ $\mathrm{TVR}=$ target vessel revascularization \\ $\mathrm{ULN}=$ upper limit of lab normal
}




\section{Introduction}

Coronary artery calcification is commonly observed in patients who undergo coronary angiography, as $73 \%$ of lesions contained calcification based upon intravascular ultrasound (IVUS).[1] Percutaneous coronary intervention (PCI) of severely calcified coronary artery lesions is technically challenging due to difficulty in advancing stents and achieving optimal stent expansion. [2] This may explain why PCI of severely calcified lesions is associated with higher rates of ischemic complications.[3]

Coronary atherectomy effectively modifies calcified plaque, facilitating stent delivery and expansion. In the ORBIT II trial, the Diamondback $360^{\circledR}$ Coronary Orbital Atherectomy System (OAS, Cardiovascular Systems, Inc., St. Paul, MN) was a safe and effective treatment strategy for severely calcified coronary lesions prior to stent delivery at 30-day and 3-year follow-up.[4,5]

The presence of calcium in chronic total occlusions (CTO) is common; calcified CTO PCI is associated with high complication rates.[6] There is no published data regarding orbital atherectomy (OA) treatment of CTOs or tight subtotal occlusions. Subtotal ( $\geq 95 \%$ stenosis) occlusions may be more complex to treat due to difficulty in traversing the lesion with the OA crown compared with lesions that are not subtotally occluded. The purpose of this ORBIT II subanalysis was to evaluate outcomes post-OA treatment of lesions with $\geq 95 \%$ stenosis.

\section{Material and methods}

Study design. ORBIT II was a prospective, non-blinded, single-arm, clinical trial that enrolled 443 consecutive subjects with severely calcified coronary lesions from 49 U.S. centers.[4] Key trial inclusion criteria included: (1) target vessel reference diameter between 2.5 to $4 \mathrm{~mm}$ with a 
stenosis $\geq 70 \%$ and $<100 \%$ or stenosis $\geq 50 \%$ and $<70 \%$ with evidence of clinical ischemia via IVUS minimum lumen area $\leq 4.0 \mathrm{~mm}^{2}$, fractional flow reserve value $\leq 0.8$, or positive stress test; (2) target lesion length $\leq 40 \mathrm{~mm}$; and (3) evidence of severe calcium deposit at the lesion site defined as presence of angiographic radio-opacities noted without cardiac motion prior to contrast injection involving both sides of the arterial wall in at least one location, total calcium length $\geq 15 \mathrm{~mm}$ that extends partially into the target lesion, or presence of $\geq 270^{\circ}$ of calcium on IVUS at one cross section. Key exclusion criteria included: (1) acute myocardial infarction (MI) (defined as creatine kinase-MB [CK-MB] > 1× upper limit of lab normal (ULN) within 30 days of the index procedure); (2) target vessel with stent from previous PCI unless the stent was in a different branch than the target lesion and was implanted over 30 days prior with no higher than 30\% in-stent restenosis; (3) chronic renal failure unless undergoing hemodialysis, or had a serum creatinine level $>2.5 \mathrm{mg} / \mathrm{dl}$; and (4) left ventricular ejection fraction $\leq 25 \%$. The use of advanced intracoronary imaging was not required as part of the ORBIT II study protocol and was left to operator discretion. All participants provided informed consent and the study was approved by each institutional review/ethics committee. Subject follow-up included a clinic visit at 30 days and telephone call or clinic visit at 1,2, and 3 years post procedure.

Study population. Subjects with the OA device activated were stratified according to preprocedure percent stenosis as assessed by the Investigator: $\geq 95 \%$ stenosis $(\mathrm{N}=91)$ and $<95 \%$ stenosis $(\mathrm{N}=341)$.

Study device. The mechanism of OA is differential sanding, in which calcified plaque is modified while it flexes away from healthy softer tissue. The eccentrically mounted diamondcoated crown spins over the ViperWire (Cardiovascular Systems, Inc.) and expands radially via centrifugal force. Increasing the time in contact with the lesion, number of passes, and rotational 
speed increase luminal gain as the crown is moved back and forth across the lesion. The elliptical orbit permits blood and micro-debris to flow past the crown, which continuously disperses the particulate. The ViperSlide (Cardiovascular Systems, Inc.) solution is infused into the drive shaft to cool the crown and reduce the risk of thermal injury to the target vessel.

Study outcomes. Procedural success was defined as successful stent delivery with a final residual stenosis of $<50 \%$ and without in-hospital major adverse cardiac events (MACE). MACE was defined as the composite of cardiac death, MI, and target vessel revascularization/target lesion revascularization (TVR/TLR). Myocardial infarction was defined as creatine kinase-myocardial band level $>3$ times upper limit of normal with or without a new pathologic Q-wave. Target vessel revascularization was defined as repeat revascularization of the target vessel (inclusive of the target lesion) after completion of the index procedure. MACE was defined as the composite of cardiac death, MI, and TVR. The angiographic core laboratory (Cleveland Clinic Foundation, Cleveland, Ohio) analyzed the procedural angiograms and reported the final minimum lumen diameter and final percentage of residual stenosis as well as the presence and type of dissections and perforations.

Statistical analysis. Continuous variables are presented as mean \pm standard deviation and categorical variables are presented as percentages. The two groups were compared using the Wilcoxon rank-sum test for continuous parameters and Fisher's exact test for categorical parameters. A Kaplan-Meier analysis with a confidence interval based on Peto's method was used to estimate the MACE rate as well as the individual components including cardiac death, MI, and TVR. Statistical comparisons of the Kaplan-Meier event rates were made using Cox proportional hazards model. Multivariable Cox proportional hazards regression was performed to identify independent predictors of 3-year TVR. Covariates in the model included: age, history of 
diabetes mellitus, smoking history (current/former vs. never), history of MI, history of coronary artery bypass grafting, eGFR ( $<50$ vs. $\geq 50)$, left ventricular ejection fraction, pre-procedure reference vessel diameter (RVD), target lesion length, pre-procedure stenosis $(\geq 95 \% \mathrm{vs} .<95 \%)$, bare metal stent vs. drug eluting stent, number of stents, and ratio of highest stent diameter to RVD. The entry criteria in the multivariable model was an alpha level of 0.20 ; significant predictors of outcomes in the final multivariable model were identified at a 0.05 alpha. Statistical analyses were performed with either SAS software system (SAS Institute, Inc) or R (R Core Team 2012; R Foundation for Statistical Computing).

\section{Results}

Subject demographics and lesion characteristics. Subjects with $\geq 95 \%$ stenosis were older $(74.2 \pm 9.1$ years vs. $70.8 \pm 10.0$ years, $\mathrm{p}=0.003)$ and had lower eGFR $(70.5 \pm 24.5 \mathrm{~mL} / \mathrm{min} / 1.73$ $\mathrm{m}^{2}$ vs. $77.0 \pm 26.7 \mathrm{~mL} / \mathrm{min} / 1.73 \mathrm{~m}^{2}, \mathrm{p}=0.042$ ) (Table 1). Otherwise, the groups were well matched in terms of baseline demographics. As shown in Table 2, compared with the $<95 \%$ stenosis group, in the $\geq 95 \%$ stenosis there were fewer left anterior descending (LAD) lesions (35.2\% vs. $56.6 \%, \mathrm{p}<0.001)$ and more right coronary artery (RCA) lesions (45.1\% vs. 25.2\%, $\mathrm{p}<0.001)$. Additionally, there were fewer Type B1 lesions in the $\geq 95 \%$ stenosis group (17.6\% vs. $28.2 \%, \mathrm{p}=0.044)$. The mean pre-procedure percent stenosis was $96.1 \%$ and $81.1 \%$, in the $\geq 95 \%$ and $<95 \%$ stenosis groups, respectively $(\mathrm{p}<0.001)$.

Procedural and angiographic results. Procedural parameters are presented in Table 3. Compared with the $<95 \%$ stenosis group, the $\geq 95 \%$ stenosis group had a smaller post-OAS minimal luminal diameter $(1.0 \pm 0.6 \mathrm{~mm}$ vs. $1.3 \pm 0.5, \mathrm{p}<0.001)$, higher post-OAS residual percent stenosis $(66.2 \pm 19.1 \%$ vs. $56.7 \pm 16.3 \%, \mathrm{p}<0.001)$, higher usage of drug-eluting stents 
$(95.0 \%$ vs. $86.8 \%, \mathrm{p}=0.013)$, and a higher maximum stent deployment pressure $(14.6 \pm 3.3 \mathrm{~atm}$ vs. $13.6 \pm 3.1$ atm, $\mathrm{p}=0.006$ ). Stents in the $<95 \%$ stenosis group were significantly shorter in length $(20.2 \pm 7.3 \mathrm{~mm}$ vs. $22.3 \pm 7.7 \mathrm{~mm}, \mathrm{p}=0.006)$ and significantly larger in diameter $(3.0 \pm$ $0.4 \mathrm{~mm}$ vs. $2.9 \pm 0.4 \mathrm{~mm}, \mathrm{p}=0.020$ ). Procedural success was $94.5 \%$ and $88.3 \%$ in the $\geq 95 \%$ stenosis and $<95 \%$ stenosis groups, respectively $(\mathrm{p}=0.120)$. The in-hospital MI rate $(\mathrm{CK}-\mathrm{MB}>$ $3 \mathrm{X}$ ULN) was higher in the $<95 \%$ stenosis group (3.3\% vs. $11.1 \%, \mathrm{p}=0.025)$; however, the MI rates did not differ using the more clinically-relevant SCAI MI definition ( $\geq 95 \%$ stenosis: $1.1 \%$ vs. $<95 \%$ stenosis: $2.3 \%, \mathrm{p}=0.692$ ).[7] The overall severe angiographic complication rates were nearly identical in both groups (6.6\% vs. 6.7\%, p>0.99) (Table 4).

30-day and 3-year MACE. There was no difference in the 30-day MACE rate in the $\geq 95 \%$ stenosis and $<95 \%$ stenosis groups $(5.5 \%$ vs. $11.7 \%, \mathrm{p}=0.099)$, or in the components of cardiac death (0\% vs. $0.3, \mathrm{p}=0.997)$ and TVR/TLR (2.2\% vs. $0.9 \%, \mathrm{p}=0.319)$ (Table 5, Figure 1$)$. However, the MI rate at 30 days was lower in the $\geq 95 \%$ stenosis group (3.3\% vs. $11.4 \%$, $\mathrm{p}=0.035)$. At 3-year follow-up, the MACE rates were similar in both groups $(27.1 \%$ vs. $22.5 \%$, $\mathrm{p}=0.55)$, as were the rates of cardiac death $(5.7 \%$ vs. $7.1 \%, \mathrm{p}=0.665)$ and $\mathrm{MI}(7.9 \%$ vs. $12.1 \%$, $\mathrm{p}=0.244)$. However, the 3 -year TVR/TLR rate was higher in the $\geq 95 \%$ stenosis group $(19.1 \%$ vs. $7.5 \%, p=0.004$ ). The final multivariable model identified $\geq 95 \%$ stenosis group [HR 2.87 (95\% CI: 1.49, 5.53), p=0.002], bare metal stent usage [HR 2.95 (95\% CI: 1.19, 7.28), p=0.019], and pre-procedure RVD [HR 0.13 (95\% CI: 0.02, 0.76), p=0.024] as independent predictors of 3year TVR (Table 6). 


\section{Discussion}

In the only analysis of its kind, the results of our analysis suggest that OA is a feasible and safe treatment for patients with severely calcified subtotal occlusions both at short and longterm follow-up. However, the TVR rate at 3 years was higher in the $\geq 95 \%$ stenosis group.

Percutaneous coronary intervention of heavily calcified coronary artery lesions that are severely stenotic may be technically more challenging compared to less stenotic lesions. Severely calcified lesions that are subtotally occluded may lead to procedural failure due to the inability to cross the lesion. More aggressive advancement of the classic crown may be required to successfully traverse the lesion. Despite the mean pre-procedure minimum luminal diameter of $0.1 \mathrm{~mm}$ in the $\geq 95 \%$ stenosis group, the procedural success rate was $94.5 \%$, which fared well compared with the $<95 \%$ stenosis group $(88.3 \%)$. The rate of severe angiographic complications was nearly identical in both groups. Despite the higher percent stenosis, the OA crown was able to treat the subtotal occlusion without a higher complication rate. In particular, the rate of persistent slow flow/no reflow was $1.1 \%$ even though the plaque burden was high in the $\geq 95 \%$ stenosis group. The perforation rate was numerically higher in the $\geq 95 \%$ stenosis group (3.3\% vs. $1.5 \%, \mathrm{p}=0.374)$. Proper OA technique, including slow advancement of the crown $(1 \mathrm{~mm} / \mathrm{s})$, may reduce the risk of perforation.[8,9] The in-hospital MI rate (CK-MB > 3X ULN) was significantly lower in the $\geq 95 \%$ stenosis group; however, when calculated using the SCAI MI definition which includes a cardiac biomarker elevation threshold which has been strongly linked to adverse clinical outcomes, the MI rates were similar in both groups.[7]

The $\geq 95 \%$ stenosis group had a higher 3-year TVR rate; as shown in the multivariable analysis, $\geq 95 \%$ stenosis group, bare metal stent usage, and decreasing pre-procedure RVD were independent predictors of 3-year TVR. The $\geq 95 \%$ stenosis group required a higher maximum 
deployment pressure, which is also consistent with the larger plaque volume. Despite this, the 3year TVR/TLR rate of $19.1 \%$ in the $\geq 95 \%$ stenosis group compares favorably with the results of the 2-year TVR rate in patients who underwent rotational atherectomy in the ROTAXUS trial (19.3\%), albeit differences in level of calcification and types of stents used.[10] There is no published rotational atherectomy study that stratified by lesion stenosis severity.

Several techniques can be utilized to enhance successful passage of the OA crown across subtotal occlusions. Optimal co-axial guide catheter positioning can provide the sufficient support to traverse the lesion. Placement of the ViperWire at the distal portion of the vessel increases stability and anchoring, providing an optimal "rail system." Placement of the crown partially into the lesion at initial activation, but not tight or fully occlusive, may facilitate crossing. A slow and steady advancement of the crown at $1 \mathrm{~mm} / \mathrm{sec}$ is preferred rather than rapidly engaging the lesion. Lastly, the use of a guide extension catheter, such as a Guideliner (Vascular Solutions, Minneapolis, MN), may facilitate procedural success by supporting the guide catheter. Additional OAS techniques and best practices can be found in recently published review articles.[8,9,11,12]

\section{Study Limitations}

This was a post-hoc subanalysis of ORBIT II - a non-randomized pivotal trial. The $\geq 95 \%$ stenosis cohort had a small number of subjects and the pre-procedure stenosis was reported by the Investigator via angiography. A stenosis of $\geq 95 \%$ may not be universally accepted as a subtotal occlusion. 


\section{Conclusions}

In the ORBIT II trial, OA treatment of lesions with $\geq 95 \%$ stenosis resulted in a high rate of procedural success. Although the 3-year revascularization rate was higher in the $\geq 95 \%$ stenosis group, it is not unexpected given the challenge of treating such complex lesions. The results of this analysis suggest that OA may be a reasonable treatment strategy for PCI of tight, severely calcified subtotal occlusions. 


\section{References}

[1] Mintz GS, Popma JJ, Pichard AD, Kent KM, Satler LF, Chuang YC, et al. Patterns of calcification in coronary artery disease. A statistical analysis of intravascular ultrasound and coronary angiography in 1155 lesions. Circulation 1995;91:1959-65.

[2] Lee MS, Shah N. The Impact and Pathophysiologic Consequences of Coronary Artery Calcium Deposition in Percutaneous Coronary Interventions. J Invasive Cardiol 2016;28:160-7.

[3] Lee MS, Yang T, Lasala J, Cox D. Impact of coronary artery calcification in percutaneous coronary intervention with paclitaxel-eluting stents: Two-year clinical outcomes of paclitaxel-eluting stents in patients from the ARRIVE program. Catheter Cardiovasc Interv 2016;88:891-7.

[4] Chambers JW, Feldman RL, Himmelstein SI, Bhatheja R, Villa AE, Strickman NE, et al. Pivotal trial to evaluate the safety and efficacy of the orbital atherectomy system in treating de novo, severely calcified coronary lesions (ORBIT II). JACC Cardiovasc Interv $2014 ; 7: 510-8$.

[5] Lee M, Généreux P, Shlofmitz R, Phillipson D, Anose BM, Martinsen BJ, et al. Orbital atherectomy for treating de novo, severely calcified coronary lesions: 3 -year results of the pivotal ORBIT II trial. Cardiovasc Revasc Med 2017;18:261-4.

[6] Karacsonyi J, Karmpaliotis D, Alaswad K, Jaffer FA, Yeh RW, Patel M, et al. Impact of Calcium on Chronic Total Occlusion Percutaneous Coronary Interventions. Am J Cardiol 2017;120:40-6. doi:10.1016/j.amjcard.2017.03.263.

[7] Moussa ID, Klein LW, Shah B, Mehran R, Mack MJ, Brilakis ES, et al. Consideration of a new definition of clinically relevant myocardial infarction after coronary revascularization: 
an expert consensus document from the Society for Cardiovascular Angiography and Interventions (SCAI). J Am Coll Cardiol 2013;62:1563-70. doi:10.1016/j.jacc.2013.08.720.

[8] Shlofmitz E, Martinsen BJ, Lee M, Rao SV, Généreux P, Higgins J, et al. Orbital atherectomy for the treatment of severely calcified coronary lesions: evidence, technique, and best practices. Expert Rev Med Devices 2017;14:867-79.

[9] Lee MS, Martinsen BJ, Shlofmitz R, Chambers JW. Coronary Orbital Atherectomy. Textb. Catheter-Based Cardiovasc. Interv., Springer, Cham; 2018, p. 681-98. doi:10.1007/978-3319-55994-0_42.

[10] de Waha S, Allali A, Büttner H-J, Toelg R, Geist V, Neumann F-J, et al. Rotational atherectomy before paclitaxel-eluting stent implantation in complex calcified coronary lesions: Two-year clinical outcome of the randomized ROTAXUS trial. Catheter Cardiovasc Interv 2016;87:691-700.

[11] Chambers JW, Behrens AN, Martinsen BJ. Atherectomy Devices for the Treatment of Calcified Coronary Lesions. Interv Cardiol Clin 2016;5:143-51.

[12] Chambers JW, Martinsen BJ. Orbital Atherectomy in the Coronary Arteries. In: Shammas NW, editor. Textb. Atherectomy, HMP Communications, LLC; 2016, p. 217-40. 


\section{Figure Legend}

\section{Figure 1. Time-to-Event Curves through 3 Years.}

Comparison of the cumulative event rates through 3-year follow-up in ORBIT II subjects with $\geq 95 \%$ pre-procedure stenosis $(\mathrm{N}=91)$ and $<95 \%$ pre-procedure stenosis $(\mathrm{N}=341)$. (A) Major adverse cardiac events. (B) Cardiac death. (C) Myocardial infarction. (D) Target vessel revascularization. 
Table 1. Subject Demographics.

\begin{tabular}{|c|c|c|c|}
\hline & $\begin{array}{c}\geq 95 \% \text { pre- } \\
\text { procedure } \\
\text { stenosis } \\
(\mathrm{N}=91)\end{array}$ & $\begin{array}{c}<95 \% \text { pre- } \\
\text { procedure } \\
\text { stenosis } \\
(\mathbf{N}=\mathbf{3 4 1})\end{array}$ & P-value \\
\hline Age (years) & $74.2 \pm 9.1$ & $70.8 \pm 10.0$ & 0.003 \\
\hline Male & $56(61.5)$ & $222(65.1)$ & 0.540 \\
\hline Ethnicity & & C) & 0.116 \\
\hline Caucasian & $85(93.4)$ & $297(87.1)$ & \\
\hline Black or African American & $2(2.2)$ & $21(6.2)$ & \\
\hline Asian & $0(0.0)$ & $8(2.3)$ & \\
\hline Hispanic or Latino & $2(2.2)$ & $13(3.8)$ & \\
\hline Native American & $0(0.0)$ & $1(0.3)$ & \\
\hline Other & $2(2.2)$ & $1(0.3)$ & \\
\hline Body mass index & $29.3 \pm 6.2$ & $29.3 \pm 5.7$ & 0.452 \\
\hline $\mathrm{eGFR}\left(\mathrm{mL} / \mathrm{min} / 1.73 \mathrm{~m}^{2}\right)$ & $\begin{array}{c}70.5 \pm 24.5 \\
(\mathrm{~N}=90)\end{array}$ & $\begin{array}{c}77.0 \pm 26.7 \\
(\mathrm{~N}=340)\end{array}$ & 0.042 \\
\hline $\mathrm{eGFR}<30 \mathrm{~mL} / \mathrm{min} / 1.73 \mathrm{~m}^{2}$ & $4(4.4)$ & $10(2.9)$ & 0.504 \\
\hline eGFR $30-50 \mathrm{~mL} / \mathrm{min} / 1.73 \mathrm{~m}^{2}$ & $13(14.4)$ & $27(7.9)$ & 0.067 \\
\hline $\mathrm{eGFR}>50 \mathrm{~mL} / \mathrm{min} / 1.73 \mathrm{~m}^{2}$ & $73(81.1)$ & $303(89.1)$ & 0.049 \\
\hline \multicolumn{4}{|l|}{ History of: } \\
\hline Diabetes mellitus & $28(30.8)$ & $127(37.2)$ & 0.271 \\
\hline Hypertension & $82(90.1)$ & $313(91.8)$ & 0.673 \\
\hline Dyslipidemia & $83(91.2)$ & $315 / 340(92.6)$ & 0.658 \\
\hline Stroke/transient ischemic attack & $9(9.9)$ & $30 / 340(8.8)$ & 0.837 \\
\hline Myocardial infarction & $18 / 88(20.5)$ & $76 / 339(22.4)$ & 0.774 \\
\hline Angina & $69(75.8)$ & $270(79.2)$ & 0.477 \\
\hline Stable & $48 / 69(69.6)$ & $169 / 270(62.6)$ & \\
\hline Unstable & $21 / 69(30.4)$ & $101 / 270(37.4)$ & \\
\hline Prior percutaneous coronary intervention & $38(41.8)$ & $160 / 337(47.5)$ & 0.346 \\
\hline Prior coronary artery bypass grafting & $18(19.8)$ & $46(13.5)$ & 0.138 \\
\hline Left ventricular ejection fraction (\%) & $56.1 \pm 10.9$ & $\begin{array}{c}56.7 \pm 9.2 \\
(\mathrm{~N}=335)\end{array}$ & 0.884 \\
\hline
\end{tabular}




\begin{tabular}{|c|c|c|c|}
\hline & $\begin{array}{c}\geq 95 \% \text { pre- } \\
\text { procedure } \\
\text { stenosis } \\
(\mathrm{N}=91)\end{array}$ & $\begin{array}{c}<95 \% \text { pre- } \\
\text { procedure } \\
\text { stenosis } \\
(\mathrm{N}=341)\end{array}$ & P-value \\
\hline Smoking & & & 0.281 \\
\hline No, Never smoked & $30(33.0)$ & $114(33.4)$ & \\
\hline Yes, Current smoker & $10(11.0)$ & $60(17.6)$ & \\
\hline Yes, Former smoker & $51(56.0)$ & $167(49.0)$ & \\
\hline \multicolumn{4}{|c|}{$\begin{array}{l}\text { Values are } \mathrm{n}(\%) \text { or mean } \pm \text { standard deviation } \\
\text { eGFR }=\text { estimated glomerular filtration rate }\end{array}$} \\
\hline
\end{tabular}


Table 2. Vessel \& Lesion Characteristics.

\begin{tabular}{|c|c|c|c|}
\hline & $\begin{array}{l}\geq 95 \% \text { pre- } \\
\text { procedure } \\
\text { stenosis } \\
(\mathrm{N}=91)\end{array}$ & $\begin{array}{l}<95 \% \text { pre- } \\
\text { procedure } \\
\text { stenosis } \\
(\mathrm{N}=341)\end{array}$ & P-value \\
\hline \multicolumn{4}{|l|}{ Target lesion vessel } \\
\hline Left anterior descending artery & $32(35.2)$ & $193(56.6)$ & $<0.001$ \\
\hline Left circumflex artery & $14(15.4)$ & $49(14.4)$ & 0.867 \\
\hline Left main coronary artery & $4(4.4)$ & $6(1.8)$ & 0.229 \\
\hline Right coronary artery & $41(45.1)$ & $86(25.2)$ & $<0.001$ \\
\hline Ramus & $0(0.0)$ & $7(2.1)$ & 0.354 \\
\hline Pre-procedure target lesion length $(\mathrm{mm})$ & $20.4 \pm 9.2$ & $18.5 \pm 8.8$ & 0.062 \\
\hline Pre-procedure average reference vessel diameter $(\mathrm{mm})$ & $3.0 \pm 0.4$ & $3.1 \pm 0.4$ & 0.047 \\
\hline \multicolumn{4}{|l|}{ ACC/AHA lesion classification } \\
\hline A & $0(0.0)$ & $0(0.0)$ & - \\
\hline B1 & $16(17.6)$ & $96(28.2)$ & 0.044 \\
\hline B2 & $42(46.2)$ & $153(44.9)$ & 0.906 \\
\hline $\mathrm{C}$ & $33(36.3)$ & $92(27.0)$ & 0.091 \\
\hline Pre-procedure minimum luminal diameter $(\mathrm{mm})$ & $0.1 \pm 0.1$ & $0.6 \pm 0.2$ & $<0.001$ \\
\hline Pre-procedure percent stenosis $(\%)$ & $96.1 \pm 1.8$ & $81.1 \pm 7.3$ & $<0.001$ \\
\hline $\begin{array}{l}\text { Subjects with calcification determined by angiography } \\
\text { only }\end{array}$ & $90(98.9)$ & $307(90.0)$ & 0.004 \\
\hline $\begin{array}{l}\text { Total length of calcium (including segmented) } \\
(\mathrm{mm})\end{array}$ & $29.9 \pm 14.5$ & $28.0 \pm 15.5$ & 0.124 \\
\hline $\begin{array}{l}\text { Subjects with calcium visible on both sides of the } \\
\text { vessel }\end{array}$ & $90(100.0)$ & $307(100.0)$ & $>0.99$ \\
\hline Subjects with calcification determined by IVUS & $1(1.1)$ & $34(10.0)$ & 0.004 \\
\hline Maximum degree of calcium via IVUS $\left(^{\circ}\right)$ & $360.0 \pm 0$ & $293.1 \pm 35.1$ & 0.152 \\
\hline \multicolumn{4}{|c|}{$\begin{array}{l}\text { ACC }=\text { American College of Cardiology, AHA = American Heart Association, IVUS = intravascular } \\
\text { ultrasound }\end{array}$} \\
\hline
\end{tabular}


Table 3. Final Overall Procedural Results.

\begin{tabular}{|c|c|c|c|}
\hline & $\begin{array}{c}\geq 95 \% \text { pre- } \\
\text { procedure } \\
\text { stenosis } \\
(\mathrm{N}=91)\end{array}$ & $\begin{array}{c}<95 \% \text { pre- } \\
\text { procedure } \\
\text { stenosis } \\
(\mathbf{N}=341)\end{array}$ & P-value \\
\hline OAS speed(s) used (rpm) & & & 0.766 \\
\hline Low only $(80,000)$ & $17(18.7)$ & $76(22.3)$ & \\
\hline Low and high $(80,000 / 120,000)$ & $70(76.9)$ & $247(72.4)$ & \\
\hline High only $(120,000)$ & $4(4.4)$ & $18(5.3)$ & \\
\hline Average individual device run time (seconds) & $\begin{array}{c}19.2 \pm 6.5 \\
(\mathrm{~N}=90)\end{array}$ & $\begin{array}{l}19.6 \pm 5.4 \\
(\mathrm{~N}=340)\end{array}$ & 0.831 \\
\hline Total device run time (seconds) & $75.3 \pm 62.8$ & $\begin{array}{l}64.5 \pm 39.6 \\
(\mathrm{~N}=340)\end{array}$ & 0.658 \\
\hline Post-OAS minimal luminal diameter $(\mathrm{mm})$ & $1.0 \pm 0.6$ & $1.3 \pm 0.5$ & $<0.001$ \\
\hline Post-OAS residual stenosis $(\%)$ & $66.2 \pm 19.1$ & $56.7 \pm 16.3$ & $<0.001$ \\
\hline Subjects treated with post-OAS/pre-stent balloon dilations & $44(48.4)$ & $133(39.0)$ & 0.119 \\
\hline Post-OAS/pre-stent balloons used per subject & $\begin{array}{l}1.4 \pm 0.8 \\
(\mathrm{~N}=44)\end{array}$ & $\begin{array}{l}1.4 \pm 0.8 \\
(\mathrm{~N}=133)\end{array}$ & 0.668 \\
\hline Maximum inflation pressure (atmospher & $\begin{array}{c}12.0 \pm 3.4 \\
(\mathrm{~N}=44)\end{array}$ & $\begin{array}{l}12.0 \pm 4.1 \\
(\mathrm{~N}=132)\end{array}$ & 0.716 \\
\hline Time at maximum pressure (seconds) & $\begin{array}{l}30.7 \pm 30.4 \\
(\mathrm{~N}=44)\end{array}$ & $\begin{array}{l}26.4 \pm 21.6 \\
(\mathrm{~N}=131)\end{array}$ & 0.709 \\
\hline Post-OAS balloon angioplasty MLD (mm) & $\begin{array}{c}1.6 \pm 0.7 \\
(\mathrm{~N}=44)\end{array}$ & $\begin{array}{l}1.9 \pm 0.6 \\
(\mathrm{~N}=131)\end{array}$ & 0.095 \\
\hline Post-OAS balloon angioplasty residual stenosis (\%) & $\begin{array}{l}46.3 \pm 22.3 \\
(\mathrm{~N}=44)\end{array}$ & $\begin{array}{l}40.5 \pm 19.5 \\
(\mathrm{~N}=131)\end{array}$ & 0.136 \\
\hline Subjects with stent placed & $89(97.8)$ & $338(99.1)$ & 0.284 \\
\hline Post-OAS stents used per subject & $\begin{array}{l}1.3 \pm 0.6 \\
(\mathrm{~N}=89)\end{array}$ & $\begin{array}{l}1.2 \pm 0.6 \\
(\mathrm{~N}=338)\end{array}$ & 0.046 \\
\hline \multicolumn{4}{|l|}{ Types of stents used in study } \\
\hline Bare metal stent & $5 / 119(4.2)$ & $54 / 417(12.9)$ & 0.007 \\
\hline Covered stent & $1 / 119(0.8)$ & $1 / 417(0.2)$ & 0.395 \\
\hline Drug-eluting stent & $113 / 119(95.0)$ & $362 / 417(86.8)$ & 0.013 \\
\hline Stent length* (mm) & $\begin{array}{l}22.3 \pm 7.7 \\
(\mathrm{~N}=115)\end{array}$ & $\begin{array}{l}20.2 \pm 7.3 \\
(\mathrm{~N}=405)\end{array}$ & 0.006 \\
\hline
\end{tabular}




\begin{tabular}{|c|c|c|c|}
\hline & $\begin{array}{l}\geq 95 \% \text { pre- } \\
\text { procedure } \\
\text { stenosis } \\
(\mathrm{N}=91)\end{array}$ & $\begin{array}{c}<95 \% \text { pre- } \\
\text { procedure } \\
\text { stenosis } \\
(\mathrm{N}=341)\end{array}$ & P-value \\
\hline Stent diameter* $(\mathrm{mm})$ & $\begin{array}{l}2.9 \pm 0.4 \\
(\mathrm{~N}=115)\end{array}$ & $\begin{array}{l}3.0 \pm 0.4 \\
(\mathrm{~N}=405)\end{array}$ & 0.020 \\
\hline $\begin{array}{l}\text { Ratio of highest stent diameter to reference vessel } \\
\text { diameter* }\end{array}$ & $\begin{array}{l}1.0 \pm 0.1 \\
(\mathrm{~N}=89)\end{array}$ & $\begin{array}{l}1.0 \pm 0.1 \\
(\mathrm{~N}=336)\end{array}$ & 0.567 \\
\hline Maximum deployment pressure (atmospheres) & $\begin{array}{l}14.6 \pm 3.3 \\
(\mathrm{~N}=89)\end{array}$ & $\begin{array}{c}13.6 \pm 3.1 \\
(\mathrm{~N}=336)\end{array}$ & 0.006 \\
\hline Post-stent residual stenosis (\%) & $\begin{array}{c}5.7 \pm 11.2 \\
(\mathrm{~N}=89)\end{array}$ & $\begin{array}{c}5.8 \pm 11.9 \\
(\mathrm{~N}=337)\end{array}$ & 0.958 \\
\hline Final procedure MLD (mm) & $\begin{array}{c}2.8 \pm 0.6 \\
(\mathrm{~N}=87)\end{array}$ & $\begin{array}{l}2.9 \pm 0.5 \\
(\mathrm{~N}=330)\end{array}$ & 0.546 \\
\hline Final procedure stenosis $(\%)$ & $5.7 \pm 14.6$ & $\begin{array}{l}4.0 \pm 13.8 \\
(\mathrm{~N}=340)\end{array}$ & 0.298 \\
\hline Total procedure time (minutes) & $50.7 \pm 31.9$ & $\begin{array}{l}52.0 \pm 28.3 \\
(\mathrm{~N}=340)\end{array}$ & 0.290 \\
\hline Total fluoroscopy time (minutes) & $\begin{array}{l}19.5 \pm 15.0 \\
\quad(\mathrm{~N}=90)\end{array}$ & $\begin{array}{l}17.4 \pm 10.8 \\
(\mathrm{~N}=338)\end{array}$ & 0.426 \\
\hline Total volume of contrast used (mL) & $\begin{array}{l}178.0 \pm 93.7 \\
\quad(\mathrm{~N}=90)\end{array}$ & $\begin{array}{l}171.1 \pm 82.4 \\
\quad(\mathrm{~N}=340)\end{array}$ & 0.646 \\
\hline Procedural success & $86(94.5)$ & $301(88.3)$ & 0.120 \\
\hline Successful stent delivery & $89(97.8)$ & $336(98.5)$ & 0.642 \\
\hline$<50 \%$ residual stenosis & $90(98.9)$ & $337(98.8)$ & $>0.99$ \\
\hline In hospital MACE & $4(4.4)$ & $39(11.4)$ & 0.049 \\
\hline Cardiac death & $0(0.0)$ & $1(0.3)$ & $>0.99$ \\
\hline Myocardial infarction (CK-MB >3X ULN) & $3(3.3)$ & $38(11.1)$ & 0.025 \\
\hline Non Q-wave & $3(3.3)$ & $35(10.3)$ & 0.037 \\
\hline Q-wave & $0(0.0)$ & $3(0.9)$ & $>0.99$ \\
\hline TVR & $1(1.1)$ & $2(0.6)$ & 0.509 \\
\hline SCAI MI & $1(1.1)$ & $8(2.3)$ & 0.692 \\
\hline
\end{tabular}




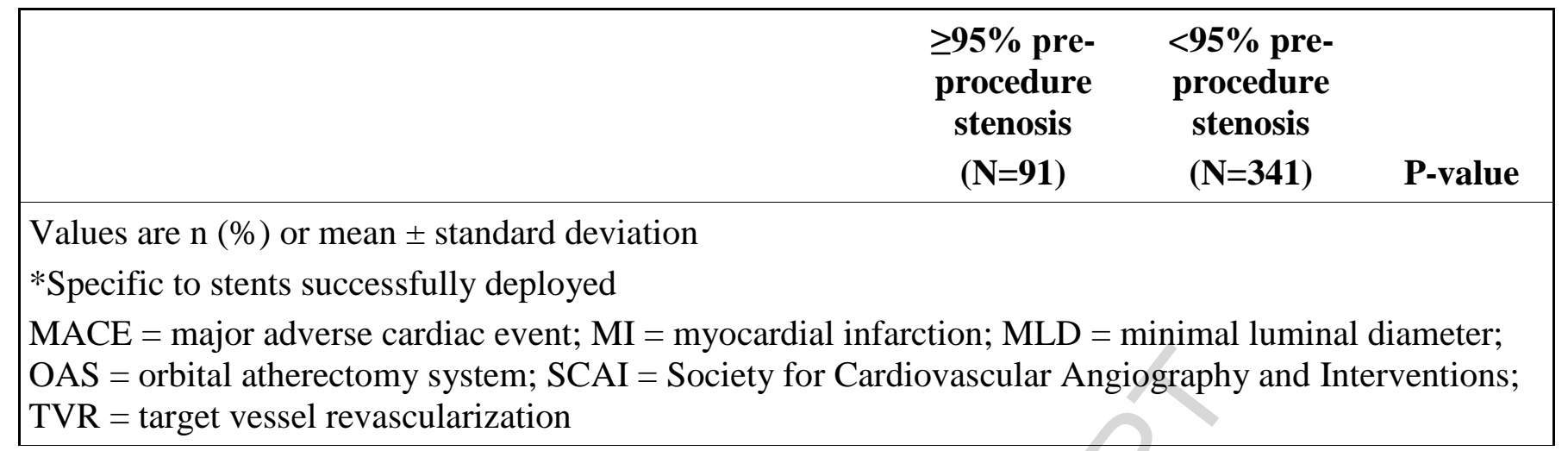


Table 4. Severe Angiographic Complications.

\begin{tabular}{|lccc|}
\hline & $\begin{array}{c}\text { 295\% pre- } \\
\text { procedure } \\
\text { stenosis } \\
(\mathbf{N = 9 1 )}\end{array}$ & $\begin{array}{c}\text { <95\% pre- } \\
\text { procedure } \\
\text { stenosis } \\
(\mathbf{N = 3 4 1 )}\end{array}$ & P-value \\
\hline Severe angiographic complications & $6(6.6)$ & $23(6.7)$ & $>0.99$ \\
\hline Severe dissection (Type C, D, E, and F) & $2(2.2)$ & $11(3.2)$ & $>0.99$ \\
\hline Perforation & $3(3.3)$ & $5(1.5)$ & 0.374 \\
\hline Persistent slow flow/no reflow & $1(1.1)$ & $2(0.6)$ & 0.509 \\
\hline Abrupt closure & $1(1.1)$ & $7(2.1)$ & $>0.99$ \\
\hline Values are n $(\%)$ & & & \\
\hline
\end{tabular}


Table 5. Cumulative MACE Rates (as estimated by Kaplan-Meier).

\begin{tabular}{|c|c|c|c|}
\hline & $\begin{array}{c}\geq 95 \% \text { pre- } \\
\text { procedure } \\
\text { stenosis } \\
(\mathrm{N}=91)\end{array}$ & $\begin{array}{c}<95 \% \text { pre- } \\
\text { procedure } \\
\text { stenosis } \\
(\mathrm{N}=341)\end{array}$ & P-value \\
\hline 30-day major adverse cardiac events & 5.5 & 11.7 & 0.099 \\
\hline Cardiac death & 0 & 0.3 & 0.997 \\
\hline $\begin{array}{l}\text { Myocardial infarction }(\mathrm{CK}-\mathrm{MB}>3 \mathrm{X} \\
\text { ULN) }\end{array}$ & 3.3 & 11.4 & 0.035 \\
\hline Non Q-wave & 3.3 & 10.3 & 0.056 \\
\hline Q-wave & 0 & 1.2 & 0.994 \\
\hline TVR/TLR & 2.2 & 0.9 & 0.319 \\
\hline TLR & 1.1 & 0.6 & 0.610 \\
\hline TVR (non-TLR) & 1.1 & 0.3 & 0.355 \\
\hline 3-year major adverse cardiac events & 27.1 & 22.5 & 0.548 \\
\hline Cardiac death & 5.7 & 7.1 & 0.665 \\
\hline $\begin{array}{l}\text { Myocardial infarction (CK-MB }>3 \mathrm{X} \\
\text { ULN) }\end{array}$ & 7.9 & 12.1 & 0.244 \\
\hline Non Q-wave & 6.6 & 10.9 & 0.236 \\
\hline Q-wave & 1.3 & 1.2 & 0.947 \\
\hline TVR/TLR & 19.1 & 7.5 & 0.004 \\
\hline TLR & 16.9 & 5.2 & 0.002 \\
\hline TVR (non-TLR) & 4.7 & 2.6 & 0.318 \\
\hline \multicolumn{4}{|c|}{$\begin{array}{l}\text { Values are } \% \\
\text { MACE = major adverse cardiac events; TLR }=\text { target lesion revascularization; TVR }=\text { target } \\
\text { vessel revascularization }\end{array}$} \\
\hline
\end{tabular}


Table 6. Analysis of Independent Predictors of 3-Year TVR

\begin{tabular}{|l|c|c|c|c|}
\hline & $\begin{array}{c}\text { Unadjusted Hazard } \\
\text { Ratio (95\% CI) }\end{array}$ & P-value & $\begin{array}{c}\text { Adjusted Hazard } \\
\text { Ratio (95\% CI) }\end{array}$ & P-value \\
\hline Pre-procedure stenosis ( $\geq 95 \%$ vs. $<95 \%)$ & $2.80[1.47,5.32]$ & 0.002 & $2.87[1.49,5.53]$ & 0.002 \\
\hline Age (per 10 years) & $1.00[1.00,1.00]$ & 0.558 & & \\
\hline History of diabetes mellitus & $0.95[0.49,1.86]$ & 0.885 & & \\
\hline Current/former smoker & $0.76[0.40,1.47]$ & 0.419 & & \\
\hline History of MI & $0.86[0.38,1.97]$ & 0.724 & & \\
\hline History of coronary artery bypass grafting & $0.91[0.36,2.33]$ & 0.846 & & \\
\hline eGFR $\left(<50\right.$ vs. $\left.\geq 50 \mathrm{~mL} / \mathrm{min} / 1.73 \mathrm{~m}^{2}\right)$ & $0.64[0.20,2.07]$ & 0.452 & & \\
\hline LVEF (per $10 \%)$ & $1.00[1.00,1.00]$ & 0.787 & & 0.024 \\
\hline Pre-procedure RVD (per 0.5 mm) & $0.14[0.02,0.80]$ & 0.027 & $0.13[0.02,0.76]$ & \\
\hline Target lesion length (mm) & $1.03[0.99,1.06]$ & 0.098 & & \\
\hline Bare metal stent vs. drug-eluting stent & $1.95[0.81,4.66]$ & 0.134 & $2.95[1.19,7.28]$ & 0.019 \\
\hline Number of stents & $0.97[0.48,1.96]$ & 0.937 & & \\
\hline Ratio of highest stent diameter to RVD & $0.03[0.00,2.96]$ & 0.136 & & \\
\hline $\begin{array}{l}\text { eGFR = estimated glomerular filtration rate; LVEF = left ventricular ejection fraction; MI = myocardial } \\
\text { infarction; RVD = reference vessel diameter; TVR = target vessel revascularization }\end{array}$ & \\
\hline
\end{tabular}




\section{Highlights}

- $\quad$ Outcomes post-OA treatment of severely calcified $\geq 95 \%$ stenosis lesions were assessed

- Procedural success and 3-year MACE were similar in $\geq 95 \%$ and $<95 \%$ stenosis groups

- Higher 3-year TVR in $\geq 95 \%$ stenosis group not unexpected given challenge of treating such complex lesions

- OA may be a reasonable treatment strategy for tight, severely calcified subtotal occlusions 


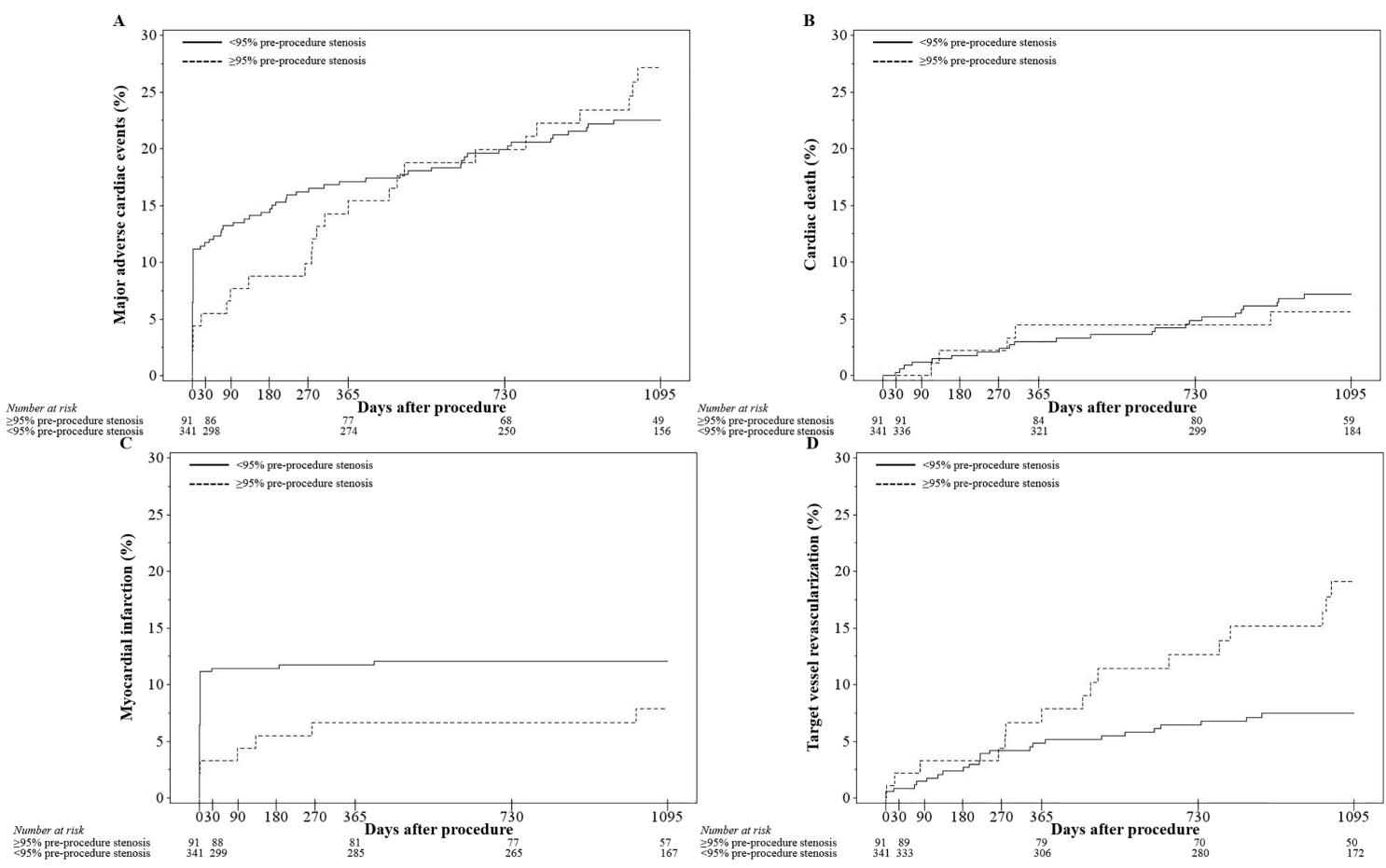

Downloaded for Anonymous User (n/a) at Indiana University - Ruth Lilly Medical Library from ClinicalKey.com by Elsevier on September 17, 2018. For personal use only. No other uses without permission. Copyright @2018. Elsevier Inc. All rights reserved.

Figure 1 